\title{
Violaciones de derechos humanos: un caso de detención arbitraria que invita a indagar y reflexionar
}

\author{
Joaquin Pablo Reca ${ }^{1}$ Universidad Nacional \\ Mariano Plaza $a^{2}$ de La Plata
}

Revista Derechos en Acción ISSN 2525-1678/ e-ISSN 2525-1686

Año 4/No 12 Invierno 2019 (21 junio a 20 septiembre), 593-606

DOI: https://doi.org/10.24215/25251678e321

\section{Introducción}

En el ámbito del derecho -sobre todo en el de los derechos humanos- se nos suelen presentar varias alternativas para encuadrar -con su posterior resolución- un hecho particular como el que detallaremos y resolveremos en el presente artículo.

Es en ese orden de ideas que advertimos la importancia -de manera preliminar- de llevar a cabo una conceptualización de las distintas opciones que se nos pueden presentar a la hora de llevar adelante un caso -ya sea como abogados, investigadores, miembros de una ONG- para poder encuadrar "de la mejor manera" el caso, lo cual nos conducirá a un mejor resultado en el mismo.

\footnotetext{
1 Abogado graduado de la Facultad de Ciencias Jurídicas y Sociales, Universidad Nacional de La Plata; Maestría en Derechos Humanos, en progreso, Facultad de Ciencias Jurídicas y Sociales, Universidad Nacional de La Plata; colaborador en la Clínica de Derechos Humanos de la Facultad de Ciencias Jurídicas y Sociales; asistente en cursos sobre la materia; expositor en seminarios y jornadas de Derechos Humanos; publicaciones sobre los distintos factores que conculcan Derechos Humanos.

2 Abogado graduado de la Facultad de Ciencias Jurídicas y Sociales, Universidad Nacional de La Plata; Maestría en Derechos Humanos, en progreso, Facultad de Ciencias Jurídicas y Sociales, Universidad Nacional de La Plata; investigador en el Observatorio de Relaciones Económicas Internacionales (OREI) de la Universidad Nacional de La Plata y coautor de informes semestrales realizados por dicho espacio académico.
} 
Es por todo esto que, consideramos relevante hacer una breve descripción de lo que se entiende por delito, crímenes internacionales y violación de derechos humanos.

\section{Caso práctico}

Lucian Padurau, ciudadano rumano, fue detenido el 27 de julio de 2006 en la puerta de su casa, en Barcelona, por cinco agentes de los Mossos d'Esquadra, que lo confundieron con otra persona. Contó que lo habían golpeado en la misma calle al detenerlo y que también habían agredido físicamente a su esposa, que estaba embarazada y se encontraba con él en ese momento. Dijo que lo habían sometido de nuevo a agresiones físicas cuando lo llevaban en un vehículo de la policía a la comisaría, además de amenazarlo con un arma y de decirle: "Más te vale tragártelo todo. Si la jueza te suelta te matamos nosotros". Los agentes continuaron golpeándolo hasta que llegaron a la comisaría de Les Corts, donde un agente de servicio en ella les advirtió: "No le peguéis más, aquí hay cámaras".

\section{III. ¿En el presente caso hay violación de derechos humanos y/o un crimen internacional y/o un delito?}

\section{III.1. Crímenes internacionales}

En lo que respecta a los crímenes internacionales, hay que destacar que si bien su tipificación constituye un gran avance y una herramienta relevante para la promoción de los derechos humanos, la corte internacional competente no es -propiamenteuna Corte de Derechos Humanos, ni una institución encargada de monitorear el cumplimiento de los derechos humanos por parte de los Estados ${ }^{3}$. Por su parte, la protección de los derechos humanos es, primordialmente, una competencia de los

3 Fernández de Gurmendi, S. (2000) “La Creación de la Corte Penal Internacional. Relaciones Internacionales". Revista Relaciones Internacionales, Instituto de Relaciones Internacionales de la Facultad de Ciencias Jurídicas y Sociales (IRI), Vol. 9 No. 19, Argentina, pp. 2 a 3.https:// 
propios Estados, ya que como se explicará más adelante son una obligación impuesta a ellos en relación a los individuos sujetos a su jurisdicción.

En esa dirección es que encontramos a la Corte Penal Internacional (en adelante la CPI), institución que fue el resultado de una larga negociación entre Estados que arribaron al consenso, por el cual "la cultura de la impunidad debía dar paso a la cultura de la responsabilidad" ", y que debían arbitrarse los modos para juzgar aquellos crímenes tan graves que no solo afectaban a las víctimas sino también ofendían la conciencia universal. Su creación surge del Estatuto de Roma de 1998, donde se establecen los lineamientos de su funcionamiento y se tipifican los delitos que juzgará; de tal modo, debemos mencionar dos características fundamentales en cuanto a su funcionamiento, como son: el juzgamiento a personas y no a Estados por parte de la CPI, siendo su competencia complementaria de la jurisdicción de los Estados y, su segunda característica versa sobre la actuación que lleva a cabo dicha Corte que solo actuará en los casos en que el Estado de que se trate no pueda o no quiera cumplir con su deber de juzgar los crímenes internacionales cometidos en su territorio. En este sentido, el artículo 17 del Estatuto establece que la Corte declarará inadmisible un caso cuando: i) el asunto sea objeto de una investigación o de acción penal por parte del Estado competente; ii) el asunto haya sido investigado por un Estado y aquel haya decidido no entablar una acción penal o iii) la persona de que se trate haya sido enjuiciada por la conducta a que se refiere la denuncia.

En cuanto a la competencia que ejerce la CPI se limitará solo a los crímenes más graves de trascendencia para la comunidad

revistas.unlp. edu.ar/RRII-IRI/article/view/1675/1615. Fecha de consulta 13 de noviembre de 2018.

4 Collantes González, J. L. (2002) "La Corte Penal Internacional. El Impacto del Estatuto de Roma en la jurisdicción sobre crímenes internacionales". Revista Electrónica de Ciencia Penal y Criminología, No. 4, España. Recuperado de http://criminet.ugr.es/recpc/recpc_04-07. html. Fecha de consulta 15 de noviembre de 2018. 
internacional, como son: el genocidio; los crímenes de lesa humanidad; los crímenes de guerra y el crimen de agresión ${ }^{5}$. Respecto a este último, como no ha podido ser aprobada una disposición en la que se lo defina, ha quedado hasta la actualidad, al margen de la competencia de la Corte.

En relación al genocidio, dicho crimen comprende: matanzas; lesiones graves a la integridad física o mental; sometimiento a condiciones de existencia que puedan acarrear la destrucción; medidas destinadas a impedir nacimientos; traslados por la fuerza de niños perpetrados con la intención de destruir total o parcialmente a un grupo nacional, étnico, racial o religioso como tal.

En tanto que los crímenes de lesa humanidad abarcan: asesinato; exterminio; esclavitud; deportación o traslado forzoso de población; encarcelación o privación grave de la libertad física; tortura; violación o cualquier otra forma de violencia sexual de gravedad comparable; persecución de un grupo o colectividad con identidad propia; desaparición forzada; crimen de apartheid, u otros actos inhumanos de carácter similar que causen intencionalmente grandes sufrimiento o atenten contra la integridad física o mental cometidos como parte de un ataque generalizado o sistemático contra una población civil y con conocimiento de dicho ataque.

Por último, los crímenes de guerra serán competencia de la CPI cuando:

...se cometan como parte de un plan o política o como parte de una comisión a gran escala de tales crímenes, y comprenden infracciones graves de los Convenios de Ginebra de 12 de agosto de 1949; otras violaciones graves de las leyes y usos aplicables en los conflictos armados internacionales dentro del marco del Derecho internacional; en caso de conflicto armado que no sea de índole internacional, las violaciones graves del artículo 3 común a los cuatro Convenios de Ginebra de 12 de agosto de 
1949; otras violaciones graves de las leyes y los usos aplicables en los conflictos armados que no sean de índole internacional, dentro del marco establecido de Derecho Internacional $^{6}$.

\section{III.2. Delito}

Por su parte, el delito común es un concepto eminentemente nacional, es decir, legislado o tipificado y perseguido por cada Estado. Un delito puede ser definido en forma general como "el incumplimiento a una norma", pero dentro de esta definición se abarca tanto al delito civil como al penal. Es por eso que delito puede ser entendido como "una acción típicamente antijurídica, culpable y adecuada a una figura penal ${ }^{7}$ o, como establece el ordenamiento jurídico español -en estudio para el caso práctico- como una "acción u omisión dolosa o imprudente penada por la ley" .

Sin entrar en mayor análisis en cuanto a los elementos del delito, surge claramente que la adecuación a una figura penal importa la previa existencia de una ley de un Estado que estableció que determinada conducta sería calificada como delito, y que le correspondería una pena.

De este modo, al resolver el caso práctico, es requerido un análisis de las leyes penales del Estado de que se trate para develar si la conducta descripta se adecúa a un tipo penal preexistente. Así, entendemos que podría encuadrarse el hecho en el artículo 167 del Código Penal español correspondiente al

6 Naciones Unidas. En línea en:

http://www.exteriores.gob.es/Portal/es/PoliticaExteriorCooperacion/NacionesUnidas/ Paginas/CortePenallnternacional.aspx. Fecha de consulta 17 de noviembre de 2018.

7 Soler, S. (1999) "Derecho Penal Argentino I", Tipográfica Editora Argentina (TEA), Buenos Aires, pp. 52 a 53. https://es.scribd.com/doc/144581136/Soler-Sebastian-Derecho-PenalArgentino-Tomo-I. Fecha de consulta 17 de noviembre de 2018.

8 Cfr. art. 10, Ley Orgánica 10/1995, 23 de noviembre, del Código Penal Español. http://noticias.juridicas.com/base_datos/Penal/lo10-1995.html. Fecha de consulta 16 de noviembre de 2018. 
"Título VI Delitos contra la Libertad, Capítulo Primero De las Detenciones Ilegales y Secuestros”, el cual establece:

"La autoridad o funcionario público que, fuera de los casos permitidos por la ley, y sin mediar causa por delito, cometiere alguno de los hechos descritos en este Capítulo será castigado con las penas respectivamente previstas en éstos, en su mitad superior, pudiéndose llegar hasta la superior en grado."

Concurrentemente podría enmarcarse el caso en el artículo 169 del "Título VI Delitos contra la Libertad, Capítulo Segundo de las Amenazas" que criminaliza la amenaza de causar a la persona "...su familia, o a otras personas con las que esté íntimamente vinculado un mal que constituya delitos...", como así también en el articulo 147 incisos 1 o 2 del "Título III De las Lesiones" dependiendo la gravedad de las lesiones sufridas por la persona.

\section{III.3. Violación de derechos humanos}

Debemos tener presente que el término violaciones de derechos humanos "no se aplica a una determinada clase de actos atroces, tal como la tortura, la desaparición forzada o el asesinato, sino, con todo rigor, a la comisión de estos actos por el Estado o sus agentes. En esta línea, se adhieren algunos teóricos de las organizaciones no gubernamentales de DD.HH. en América Latina, quienes insisten en esta diferencia elemental entre lo que es un delito (cometido por personas particulares) y una violación de derechos humanos (cometida por el Estado)"9

Asimismo, organismos internacionales -como la Oficina del Alto Comisionado para los Derechos Humanos- han manifestado los supuestos en los que se estaría en presencia de una violación de derechos humanos, sosteniendo que:

9 Huhle, R. (1993) "La violación de los derechos humanos. ¿Privilegios de los Estados?", Revista Memoria N ${ }^{\circ}$, de Dokumentations und Informationszentrum Menschenrechte in Lateinamerika, KO`AGA ROÑE’ETA se.iv. http://www.derechos.org/koaga/iv/1/huhle.html. Fecha de consulta 12 de diciembre de 2018. 
As an abstract entity, however, a State does not "act" by itself, but rather through its agents, who may be individually identifiable.

To make a finding that a human rights violation has occurred, an investigative body must be satisfied, to the standard of proof adopted, that:

(a) the incident or violation occurred under the substantive buman rights law (e.g., probibition of torture or discrimination); and

(b) the State itself or its agent(s) carried out the act, or omission, that comprised the violation ${ }^{10}$.

Lo expuesto se puede traducir en la idea del Estado como una "entidad abstracta" que no actúa por sí solo, sino a través de sus agentes, quienes pueden ser individualmente identificables; además, para hacer una constatación de que se ha producido una violación de los derechos humanos, un órgano de investigación debe estar satisfecho, según el estándar de prueba adoptado, de que la violación ocurrió de acuerdo a legislación sustantiva de derechos humanos (por ejemplo, la prohibición de la tortura o la discriminación); y que el propio Estado o sus agentes llevaron a cabo el acto u omisión que conformó la violación.

\section{Resolución del caso}

\section{IV.1. Incumplimiento de instrumentos internacionales: violaciones de derechos humanos}

En virtud de lo hasta aquí mencionado, es que en el presente caso estaríamos en presencia tanto de un delito como de una violación de derechos humanos por el accionar de los agentes del Estado.

\footnotetext{
10 United Nations Human Rights, Office of the High Commissioner (2018) "Who's responsible? Attributing individual responsibility for violations of international human rights and humanitarian law in United Nations commissions of inquiry, fact-finding missions and other investigations", New York and Geneva, pp. 29 a 30. https://www.ohchr.org/Documents/Publications/Attributin glndividualResponsibility.pdf. Fecha de consulta 17 de noviembre de 2018.
} 
En este último vemos - de manera cronológica respecto al actuar de los Mossos d’Esquadra- cómo se conculcan derechos y garantías que se plasman en diversos instrumentos internacionales de derechos humanos tales como detención arbitraria (cfr. arts. 9, Declaración Universal de Derechos Humanos -en adelante DUDH-; 9, Pacto Internacional de Derechos Civiles y Políticos $^{11}$-en adelante ICCPR-; 5 incs. 1 y 2, Convenio Europeo para la Protección de los Derechos Humanos y de las Libertades Fundamentales $^{12}$-en adelante CEDH- y 6 inc. 4, Convención Contra la Tortura y otros Tratos o Penas Crueles, Inhumanos o Degradantes $^{13}$-en adelante UNCAT-).

Cabe mencionar en el caso de la DUDH que si bien no tiene fuerza obligatoria por tratarse de una declaración y no de un tratado, no deja de tener una notoria importancia y que, dada su connotación histórica-simbólica para la comunidad internacional, la misma no deja de ser un "documento vivo", siendo su espíritu trasmitido a una serie de convenios y pactos de la comunidad de los Estados participantes de las Naciones Unidas -en adelante ONU-, así como el ICCPR de 1966, la UNCAT de 1984 y muchos más, que sí son tratados internacionales que obligan a los Estados ratificadores a cumplir con ellos. Por eso, es que dicha declaración es la "piedra angular" de los derechos reflejados en los distintos instrumentos internacionales de derechos humanos y, por los cuales luchan asiduamente las distintas ONGs regionales e internacionales; de igual modo, la trascendencia de la DUDH la vemos puesta de manifiesto en distintos ordenamientos jurídicos, como es el caso de España que, en materia interpretativa, prevé: "Las normas relativas a los

\footnotetext{
11 España realizó el depósito de la ratificación el 27 de abril de 1977. http://www.sinrefugio.org/noentra/PDF/cast/tratados.pdf. Fecha de consulta 4 de diciembre de 2018.

12 España realizó el depósito de la ratificación el 4 de octubre de 1979, publicado en el boletín oficial del estado el 10 de octubre de 1979. http://www.sinrefugio.org/noentra/PDF/ cast/tratados.pdf. Fecha de consulta 4 de diciembre de 2018.

13 España realizó el depósito de la ratificación el 21 de octubre de 1987. http://www. sinrefugio.org/noentra/PDF/cast/tratados.pdf. Fecha de consulta 4 de diciembre de 2018.
} 
derechos fundamentales y a las libertades que la Constitución reconoce se interpretarán de conformidad con la Declaración Universal de Derechos Humanos...”.

Otro de los derechos que observamos transgredido es el referido a la tortura (cfr. arts. 1, $\mathrm{UNCAT}^{14}$; 5, DUDH; 3, CEDH; 2 inc. 1, ICCPR).

Por otro lado, entendemos como dato relevante el de la nacionalidad de la persona detenida "...ciudadano rumano...", lo cual nos permite conjeturar que los derechos conculcados -mencionados con antelación- orbitan en la esfera de la discriminación (cfr. arts. 1 inc. $1^{15}$, Convención Internacional sobre la Eliminación de todas las Formas de Discriminación Racial ${ }^{16} 2$, DUDH; 7, ICCPR y 14, CEDH).

No se debe hacer caso omiso de la agresión física sufrida por la esposa del detenido. Esta circunstancia nos habilita a sostener que, si bien los instrumentos en materia de derechos humanos aludidos en párrafos anteriores hacen a la dignidad ${ }^{17}$ de todo "ser humano", creemos necesario que para llevarse a

14 Dicho artículo -en su primer apartado- edifica los presupuestos para poder hablar de "tortura", entendiendo a aquella como "... todo acto por el cual se inflija intencionalmente a una persona dolores o sufrimientos graves, ya sean físicos o

15 Este catálogo reza que "discriminación racial" denota "...toda distinción, exclusión, restricción o preferencia basada en motivos de raza, color, linaje u origen nacional o étnico que tenga por objeto o por resultado anular o menoscabar el reconocimiento, goce o ejercicio, en condiciones de igualdad, de los derechos humanos y libertades fundamentales en las esferas política, económica, social, cultural o en cualquier otra esfera de la vida pública". https://www. humanium.org/es/convencion-internacional-sobre-la-eliminacion-de-todas-las-formas-dediscriminacion-racial/. Fecha de consulta 14 de diciembre de 2018.

16 Ratificado por España en el año 1984. http://indicators.ohchr.org/. Fecha de consulta 4 de diciembre de 2018.

17 Algunos autores la ha definido de "Un valor singular que se nos presenta como una llamada al respeto incondicionado y absoluto y del cual se desprenden diversos principios, tales como: principio de respeto, de no-malevolencia y benevolencia", Bota, J. V. (2009), "Valores y Principios - La Dignidad Humana y sus implicancias éticas", Asociación Catalana de Estudios Bioéticos (ACEB), Cap. IV "La dignidad humana, un valor fundamental". http://bioetica.cat/ valores-y-principios-la-dignidad-humana-y-sus-implicaciones-eticas/. Fecha de consulta 6 de diciembre. 
cabo una investigación satisfactoria es imprescindible prestar atención a la protección específica que dichos catálogos internacionales dedican a ciertos colectivos (v. gr. personas con discapacidad, comunidades originarias o, como se presenta en el caso, respecto de la mujer a través de la "Convención sobre la Eliminación de toda las Formas de Discriminación contra la Mujer" -en adelante CEDAW- ${ }^{18}$.

Por lo que advertimos una conveniencia en el tratamiento específico -de ciertos colectivos- que realizan los documentos de derechos humanos, como sucede con la CEDAW, ya que no solo pone de resalto el avance en la materia estudiada sino también, la edificación de un "vallado infranqueable" frente a las potestades de los Estados.

\section{IV.2. Responsabilidad estatal}

De manera preliminar debemos acentuar que el acontecimiento tomó lugar en una "comunidad autonómica", como es la de Cataluña, por lo que habría que preguntarse si le cabe algún tipo de responsabilidad frente a la comunidad internacional.

En esa línea, debe considerarse al respecto lo dictaminado por el Tribunal Constitucional de España ${ }^{19}$, el cual reconoce que las comunidades autónomas pueden llevar a cabo actividades con proyección exterior pero recuerda que -en todo caso- se debe respetar la competencia exclusiva del Estado en materia de relaciones internacionales, tal y como prevé el artículo 149.1.3 de la carta magna española. ${ }^{20}$

\footnotetext{
18 España realizó el depósito de la ratificación el 5 de enero de 1984. http://www.sinrefugio.org/noentra/PDF/cast/tratados.pdf. Fecha de consulta 13 de diciembre de 2018.

19 Cfr. art. 159 y ss., Constitución española, promulgada el 27 de diciembre de 1978. https:// www.boe.es/legislacion/documentos/ConstitucionCASTELLANO.pdf. Fecha de consulta 15 de diciembre de 2018.

20 Sentencia 77/2017, de 21 de junio (BOE núm. 171, de 19 de julio 2017), ECLI:ES:TC:2017:77. http://hj.tribunalconstitucional.es/es/Resolucion/Show/25386. Fecha de consulta 6 de diciembre de 2018.
} 
De lo anterior inferimos, que la responsabilidad internacional recaería en cabeza del Estado español por el accionar de los Mossos d'Esquadra.

Habiendo dicho esto, lo siguiente que deberíamos preguntarnos es, ¿qué tipo de responsabilidad se le debiera endilgar a España en el caso que nos convoca?

La responsabilidad de los Estados en casos de violación de derechos humanos puede definirse en tres niveles. Teniendo en cuenta que los Estados tienen el deber de respetar, proteger y garantizar los derechos humanos para todas las personas bajo su jurisdicción, la responsabilidad que les cabe es por acción, omisión o falta de debida diligencia respectivamente. De esta manera, en un primer plano de análisis la responsabilidad del Estado español es por acción, ya que la actuación de agentes estatales produjo una violación de derechos humanos plasmados en instrumentos internacionales ratificados por España y, consecuentemente, violó el deber de "respetar".

En este caso, reparamos en el hecho de que la detención del ciudadano rumano versa tanto de un delito como de una violación de derechos humanos, por lo que correspondería la actuación del Poder Judicial local para evitar que el Estado español incurra en responsabilidad internacional por la violación de derechos humanos y, así, se habilite así la instancia internacional. Si el aparato judicial actúa y resuelve el caso satisfactoriamente, cesaría la violación de derechos humanos al ser éstos una obligación entre el Estado y los individuos bajo su jurisdicción.

Por lo tanto, convenimos en la responsabilidad del Estado subsidiaria a la investigación local. Si el Estado no investiga y el caso va al ámbito internacional, habrá entonces responsabilidad del Estado por violación de derechos humanos.

Por otro lado, y como se expresa infra, el Estado español podría ser pasible de responsabilidad por falta de debida diligencia en el caso de fallar en la "garantía" del goce de derechos humanos. 


\section{IV.3. Los derechos humanos y su debida diligencia}

En el ámbito internacional de los derechos humanos es latente la preocupación respecto de la tortura, por la cual los Estados se han ido comprometiendo -por medio de las ratificaciones de los distintos instrumentos internacionales- a perseguirla, prevenirla y en su caso a penarla con la debida contundencia sin dejar ningún espacio a la impunidad.

A pesar de que 165 Estados han ratificado la UNCAT $^{21}$ la tortura sigue presente en al menos 98 países y en todas las regiones del mundo. En muchos es un delito oculto que permanece en las sombras y la impunidad.

Este es el caso de España donde, si bien no de forma sistemática, la tortura y los malos tratos son demasiado frecuentes para considerarlos excepciones anecdóticas.

Lo han denunciado los organismos internacionales, desde el Comité de Derechos Humanos y el Comité Contra la Tortura de Naciones Unidas, el Tribunal Europeo de Derechos Humanos $^{22}$ hasta organizaciones independientes de defensa de los Derechos Humanos.

El persistente incumplimiento de las recomendaciones hechas por organismos internacionales para su prevención o para la adecuación de la definición de tortura en el Código Penal español con la UNCAT son síntomas graves de una falta de voluntad política de atajar esta práctica desde las responsabilidades del Estado.

Por eso, y frente a la inacción del Estado español, v. gr. falta de adecuación de la tipificación del delito de tortura en el

\footnotetext{
21 Nueva Tribuna. https://treaties.un.org/pages/ViewDetails.aspx?src=IND\&mtdsg_no=IV9\&chapter=4\&lang=en. Fecha de consulta 12 de diciembre de 2018.

22 El 31 de mayo de 2016 el Tribunal Europeo de Derechos Humanos condenó a España en el caso "Beortegui Martínez c. España" (Demanda n³6286/14), mediante el cual se fijó una indemnización de 20.000 euros por daños morales y 3.500 euros de costas, debido a las torturas que alegó la parte actora sufridas por la Guardia Civil. Esta sentencia, creemos, es de gran relevancia debido a que la misma nos alerta sobre prácticas que se manejan con cierta asiduidad (casos centinelas).
} 
Código Penal en relación a la definición de la Convención, como tampoco tomar medida alguna para salvaguardar a las personas en régimen de incomunicación o la falta de profundización de programas educativos sobre la prohibición de la tortura a los agentes de la fuerza del orden, entre otras estimamos que se le debiera atribuir responsabilidad.

\section{Hipótesis vs. Realidad: ¿cómo terminó el caso?}

"La Audiencia de Barcelona ha condenado a seis años y siete meses de cárcel a tres Mossos d'Esquadra por las torturas y lesiones infligidas a un rumano que fue confundido con un delincuente. Cuando se produjo la detención, Lucian P. iba acompañado de su novia, embarazada de dos meses, que también recibió un trato degradante de otros dos agentes. Uno ha sido condenado a dos años y tres meses de cárcel y otro a 2.400 euros de multa. Ésta es la sentencia más dura dictada contra los agentes de la policía autonómica catalana en los 25 años que ahora se cumplen de su despliegue".

"Lucian P. , de 28 años, se marchó hace cuatro meses a Rumania, donde trabaja de albañil. 'No tengo ningún interés en volver', explicó ayer en conversación telefónica con EL PAÍS. Se casó con su novia y tuvieron un hijo, pero no ha olvidado lo sucedido. 'Sigo pensando en lo ocurrido y cuando quedé en libertad siempre miraba para atrás', explica. Está 'bastante satisfecho con la sentencia y asegura que confiaba en la Justicia. Por eso llegué tan lejos, aunque pasé mucho miedo en el juicio"’3.

"Iván Fernández, abogado de la víctima, mostró ayer su satisfacción con la sentencia. El Departamento del Interior de la Generalitat de Cataluña aseguró ayer que la está analizando para decidir las medidas jurídicas y laborales que adoptará"24.

\footnotetext{
23 Diario El País. En línea en: https://elpais.com/diario/2008/11/26/espana/1227654009_ 850215.html, segundo párrafo. Fecha de consulta 12 de diciembre de 2018.

24 https://elpais.com/diario/2008/11/26/espana/1227654009_850215.html, sexto párrafo. Fecha de consulta 12 de diciembre de 2018.
} 


\section{Conclusión}

Resulta singularmente interesante el caso trabajado en esta oportunidad.

Indudablemente, en el mismo se pone en juego la complejidad jurídica y operativa del tema frente a una situación dada; aspecto que nos ha llevado a indagar con el estilo sinóptico que caracteriza este tipo de labor sobre las circunstancias que enmarcan el efectivo derecho aplicable y -naturalmente- la complejidad que da razón y tipifica el alcance de los derechos humanos. En este sentido, no es posible soslayar el universo del ordenamiento jurídico, sus tribunales (resoluciones) y, por ende, los contenidos punitivos propios de cada país, enlace necesario con lo previsto en el terreno internacional.

Todo lo cual, resulta enriquecedor en la búsqueda de la imperiosa certeza que deben guiar los propósitos de toda investigación de violación de derechos humanos. 